\title{
A ORGANIZAÇÃO MUNDIAL DA PROPRIEDADE INTELECTUAL E A NECESSIDADE DE ADOÇÃO TRANSNACIONAL DE MEDIDAS PARA PROMOÇÃO DAS PATENTES VERDES
}

\author{
THE WORLD INTELLECTUAL PROPERTY ORGANIZATION AND THE \\ TRANSNATIONAL NECESSITY FOR MEASURES TO PROMOTING OF GREEN \\ PATENTS
}

\author{
${ }^{1}$ Marcos Vinicius Viana da Silva \\ ${ }^{2}$ José Everton da Silva
}

\section{RESUMO}

O presente trabalho objetiva entender se a promoção das patentes verdes deve ocorrer via incentivo estatal, ou através de medidas editadas pela própria OMPI. Como hipótese de pesquisa, acredita-se que a OMPI direcionou as medidas protetivas para a esfera estatal, o que não supre a demanda transnacional no caso das patentes. Para a realização deste artigo fora utilizado o método indutivo e da revisão bibliográfica. Como conclusão, verificou-se que medidas adotadas no âmbito nacional podem representar avanços no campo das patentes verdes, porém para que o incentivo ocorra de forma plena é necessário uma maior participação dos organismos internacionais.

Palavras chave: Patente; Patente Verde; Propriedade Industrial; Organização Mundial da Propriedade Intelectual, Transnacionalidade.

\begin{abstract}
This study aims to understand if the promotion of green patents should occur through domestic way, or by measures issued by the WIPO. As a research hypothesis, it is believed that WIPO directed the protective measures to state level, which does not supply the transnational demand in patents case. For the realization of this article had been used inductive and literature review method. In conclusion, it was found that measures taken at the national level may represent advances in the field of green patents, but for which the incentive is full form greater participation by international agencies is needed.
\end{abstract}

Keywords: Patent; Green Patent; Industrial property; World Intellectual Property Organization, Transnationality.

\footnotetext{
${ }^{1}$ Doutorando em Ciência Jurídica pela Universidade do Vale do Itajaí - UNIVALI, Santa Catarina, (Brasil). Professor Universitário das Matérias de Direito Eleitoral, Propriedade intelectual, Direito Internacional e Direito Constitucional. E-mail: mvsilva0805@gmail.com

${ }^{2}$ Doutor em Ciência Jurídica pela Universidade do Vale do Itajaí - UNIVALI, Santa Catarina, (Brasil). E-mail: caminha@univali.br
} 


\section{INTRODUÇÃO}

A organização mundial de propriedade intelectual, em português OMPI e na sigla em Inglês WIPO, lançou no final da década de 2000 uma lista de produtos que seriam benéficos ao meio ambiente, e que acabariam por promover a sustentabilidade, ao menos na esfera ambiental.

Todavia, apesar de ter informado quais seriam as áreas sensíveis do conhecimento que mereciam o tratamento diferenciado, acabou por deixar a cargo dos países a forma com que a promoção ocorreria na prática, evidenciando apenas que os incentivos deveriam ocorrer dentro do campo administrativo de cada país.

Dito isto, o objetivo do presente artigo é verificar, inicialmente, quais foram os países que protegeram as patentes verdes, e em caso positivo para a nação brasileira, compreender ao menos como outra nação realizou a promoção desta forma patentária. Com esta resposta inicial, buscar-se-á responder ao questionamento principal da pesquisa, que pode ser expresso da seguinte forma: é necessário uma padronização transnacional no campo da proteção das patentes verdes?

No tocante a hipótese de pesquisa, acredita-se que existe um grupo razoável de países que buscou proteger as patentes verdes, e que as formas de incentivo adotadas pelos países ocorreram de forma relativamente semelhantes. Já relacionado a pergunta principal, acreditase que ao delegar aos Estados o dever de estabelecer as medidas protetivas da patente verde, a OMPI acabou por minimizar os efeitos positivos da promoção desta forma de patente, devendo ser adotada uma medida transnacional pela própria instituição.

Para que seja possível confirmar ou refutar as hipóteses propostas, dividiu-se a pesquisa em três itens, que se complementam e dão profundidade ao tema estudado. No item um, tratar-se-á do sistema de patentes em geral, da propriedade industrial e do conceito de patente verde.

No segundo item, o artigo irá abordar em que locais as patentes verdes foram protegidas, comparando ao menos dois países em relação aos mecanismos pelos quais tal forma de patente foi promovida. Por fim, no item três, discutir-se-á a figura da OMPI no processo transnacional de patentes, bem como seu possível dever institucional de promotora de medidas transnacionais para o real incentivo das patentes verdes na esfera internacional.

Referente a metodologia, será utilizado o método indutivo ${ }^{3}$, tanto para coleta dos

\footnotetext{
3 “MÉTODO INDUTIVO: base lógica da dinâmica da Pesquisa Científica que consiste em pesquisar e identificar
} 
dados quanto no tratamento dos mesmos. Já no tocante as técnicas, serão utilizadas as técnicas do Referente ${ }^{4}$, da Categoria ${ }^{5}$, do Conceito Operacional ${ }^{6}$ e da Pesquisa Bibliográfica ${ }^{7}$.

\section{A PROPRIEDADE INTELECTUAL}

Ao tratar de sistema patentário, no qual se enquadra a patente verde, é imperioso informar que seu estudo está situado dentro de uma lógica maior, qual seja o da propriedade intelectual. Área jurídica estabelecida dentro do direito empresarial, mas que possui considerável independência acadêmica.

Os direitos de propriedade intelectual encontram-se garantidos primeiramente na Constituição Federal, em seu art. $5^{\circ}$, inciso XXVII e seguintes, do qual se pode destacar a presente citação: "Aos autores pertence o direito exclusivo de utilização, publicação, ou reprodução de suas obras, transmissível aos herdeiros no tempo em que a lei fixar." (BRASIL, 1988)

Todavia, ao informar a proteção constitucional não se expressa o conceito do tema, ou mesmo a abrangência da propriedade intelectual, assim, é necessário a apresentação de um conceito operacional para o tema, exteriorizado neste artigo pelo dizeres de Pimentel. (2005, p.17)

O Direito de Propriedade Intelectual brasileiro compreende hoje o conjunto da legislação federal, oriunda do legislativo e executivo, de caráter material, processual e administrativo. Este Direito abrange as espécies de criações intelectuais que podem resultar na exploração comercial ou vantagem econômica para o criador ou titular e na satisfação de interesses morais dos autores.

Isto posto, é possível compreender que a propriedade intelectual é aquela ligada a uma criação mental do homem, representado em um direito imaterial, que muitas vezes carrega maior importância que a própria materialidade do invento.

Dentro desta esfera do direito encontra-se a propriedade industrial, que é o ramo do direito que visa proteger a produção intelectual humana inerente aos produtos e aplicações

as partes de um fenômeno e coleciona-las de modo a ter uma percepção ou conclusão geral”. (PASOLD, 2011, p. 205).

4 “REFERENTE: explicitação prévia do motivo, objetivo e produto desejado, delimitando o alcance temático e de abordagem para uma atividade intelectual, especialmente para uma pesquisa. (...)". (PASOLD, 2011, p. 209).

5 “CATEGORIA: palavra ou expressão estratégica à elaboração e/ou à expressão de uma ideia.” (PASOLD, 2011, p. 197).

6 “CONCEITO OPERACIONAL [COP]: definição estabelecida ou proposta para uma palavra ou expressão, com o propósito de que tal definição seja aceita para os efeitos das ideias expostas.” (PASOLD, 2011, p. 198).

7 "PESQUISA BIBLIOGRÁFICA: Técnica de investigação em livros, repertórios jurisprudenciais e coletâneas legais." (PASOLD, 2011, p. 207). 
voltadas ao conhecimento e produção industrial. Dito isto, tratar-se-á primeiramente da propriedade industrial e em sequência das patentes verdes propriamente ditas.

\subsection{Da Propriedade Industrial}

Conforme narrado anteriormente, a propriedade industrial é denominada para toda e qualquer produção de produtos ou serviços que possuam alguma aplicação na indústria, e que por consequência a este pressuposto sejam capazes de gerar algum tipo de lucro para aquele que produz a invenção ou ainda a explora.

Dentro deste ramo existe uma divisão clássica, que define como ramos da propriedade das industrias as patentes de invenção, os modelos de utilidade, os desenhos indústrias, as marcas, as indicações geográficas e a concorrência desleal. (WACHOWICZ, 2010, p.14)

A regulamentação desta área acadêmica está legalmente definida pela Lei $\mathrm{n}^{\circ}$ 9.279, de 14 de maio de 1996, também denominada da Lei da Propriedade Industrial, ou apenas LPI, que traz como principais direitos de toda a propriedade industrial, bem como aponto as características básicas para garantia-los. (INPI, 2016)

Dentro os diversos direitos apresentados pela norma, é considerado direito basilar aquele que representa a exclusividade na exploração, produção ou alienação do bem ou serviço desenvolvido, possibilitando assim ao inventor receber alguma espécie de lucro. Sobre o tema Tafforeau (2004, p.130) explana: “Le droit d'exploitation est l'ensemble de prerógativequipermettent à l'auteur de subordonnel'utilisation de sesouvresaupaiement d'une remunerátion."

Todavia, para que o direito da propriedade industrial seja assegurado, algumas medidas devem ser tomadas, dentre as quais se destaca a necessidade de registro no INPI (Instituto Nacional da Propriedade Industrial), além do pagamento de taxas administrativas.

Outrossim, as criações no campo da propriedade industrial, tais como as invenções, modelos de utilidade e desenhos industriais, dependem de requisitos como: de novidade, aplicação industrial, atividade inventiva. (BINCTIN, 2010, p.10)

Descritos estes pontos gerais da propriedade industrial, analisar-se-á em seguida como foram determinadas e instituídas as patentes no ordenamento jurídico brasileiro, levando-se em consideração que sua existência segue regramentos internacionais delimitados por tratados e instituídos e fomentados pela OMPI. 


\subsubsection{Das Patentes De Invenção}

Introdutoriamente, informa-se que apesar de possíveis peculiaridades especificas, as características de uma patente de invenção se assemelham em quase todos os países. Sendo, portanto, oportuno apresentar o conceito de patente de invenção, que nas palavras de Santos (2001, p.12) representa "O título concedido pelo Estado ao autor de uma criação inventiva, de utilidade industrial, na forma de invenção, garantindo-lhe a propriedade e o uso exclusivo, por lapso temporal estabelecido em lei”.

Informando o conceito, aduz-se que segundo a Lei nº 9.279, os requisitos básicos para a patenteabilidade de uma invenção estão estipulados no artigo $8^{\circ}$, que assim informa: "É patenteável a invenção que atenda aos requisitos de novidade, atividade inventiva e aplicação industrial” (BRASIL, 1996).

Assim, são três os requisitos mínimos para a concessão da proteção Estatal, o primeiro deles à novidade, está conectado com o desenvolvimento de um produto que o diferencia do estado da técnica. Em outras palavras, o estado da técnica é o modelo em que se encontra determinado produto ou método, antes de o inventor depositar seu pedido de patente. Significaria que o que as pessoas já conhecem relacionado a um produto seria considerado o estado da técnica, neste sentido não se pode proteger algo que já é conhecido, ferindo assim a inovação. (DEL NERO, 2004)

Já a atividade inventiva constitui tudo aquilo que, para um técnico no assunto, não decorra de maneira óbvia do estado da técnica. Trata-se, portanto, de um trabalho intelectual diferenciado realizado pelo inventor, que se utiliza de métodos ou caminhos não comuns ao técnico daquele assunto. (BRASIL, Lei. 9.279, 1996, Art.11º)

Por fim, a patenteabilidade verifica-se através de um aspecto utilitarista, que ocorre quando a mesma pode ser aplicada às indústrias em geral, de forma ampla tal aspecto é o mais versátil dos apresentados para a concessão de uma patente, uma vez que praticamente tudo que for novo torna-se aplicável a indústria atual. (BARBOSA, 2007, p.18)

Assim, em suma, para algo ser patenteado como invenção deve ser novo, ser elaborado de uma forma que o técnico não considera obvio, e útil industrialmente. Tais aspectos correspondem ao valor social da invenção, em sua estrutura como um trabalho intelectual que visa o desenvolvimento econômico e tecnológico.

Possuindo o produto os requisitos necessários apresentados acima, deve o inventor realizar o pedido administrativo ao INPI, que realizará uma análise do objeto, buscando 
verificar se ele realmente apresenta as características necessárias, bem como se foi realizado o pagamento das taxas estatais pertinentes. (DIRPA, 2016)

Em contrapartida ao esforço do inventor, o Estado concede a ele o direito de exploração, narrada anteriormente, pelo prazo fixo de 20 anos, independe do objeto que está sendo protegido, e posteriormente a este período o bem cai em domínio público, podendo ser utilizado por qualquer pessoa em qualquer localidade do mundo. (BARBOSA, 2007)

Uma vez estabelecido o que uma patente de invenção e o que é necessário para sua concessão, apresenta-se no final do primeiro item o conceito geral das patentes verdes.

\subsection{O Instituto das Patentes Verdes.}

O tema patente verde teve origem na OMPI - Organização Mundial da Propriedade Industrial no ano de 2009, quando fora editada uma proposta em que algumas patentes deveriam possuir prioridade em relação a outras, devido sua importância para o meio ambiente. $^{8}$

Esta proposta estava diretamente relacionada com conceitos da Agenda 21, que trazia a importância da proteção de tecnologias sustentáveis:

São tecnologias que protegem o meio ambiente; são menos poluentes; utilizam todos os recursos de uma forma mais sustentável; reciclam mais resíduos e produtos e tratam os dejetos residuais de uma maneira mais aceitável. ${ }^{9}$

Os temas patenteáveis que foram selecionados pela OMPI para proteção especial foram Energia alternativa, Transporte, Conservação de energia, Gerenciamento de resíduos, Agricultura, Energia Nuclear e normas e regulamentos administrativo. Segundo a OMPI, a proteção a estes produtos deveria ocorrer de maneira a facilitar seu desenvolvimento, aprimorando e ampliando assim a sustentabilidade no âmbito global.

Não fora do eixo desta pesquisa, informa-se que neste estudo é utilizado o conceito de sustentabilidade descrito por Freitas (2009, p.34), que apresenta o tema como sendo “[...]pensar em referencias arrojadas, com respeito consciente e pleno à titularidade dos

\footnotetext{
${ }^{8}$ The "IPC Green Inventory" was developed by the IPC Committee of Experts in order to facilitate searches for patent information relating to so-called Environmentally Sound Technologies (ESTs), as listed by the United Nations Framework Convention on Climate Change (UNFCCC).

${ }^{9}$ A Agenda 21 foi um dos principais resultados da conferência Eco-92 ou Rio-92, ocorrida no Rio de Janeiro, Brasil, em 1992. É um documento que estabeleceu a importância de cada país a se comprometer a refletir, global e localmente, sobre a forma pela qual governos, empresas, organizações não-governamentais e todos os setores da sociedade poderiam cooperar no estudo de soluções para os problemas socioambientais.
} 
direitos daqueles que ainda não nasceram e à ligação de todo os seres, acima das coisas"

De forma mais especifica o objetivo das patentes verdes era de promover uma sustentabilidade principalmente ambiental, fazendo assim uma menor deterioração do meio ambiente. Dito isto, é nítido que a patente verde criada pela OMPI possui a função de promoção de medidas que ampliem a sustentabilidade, tendo apenas se ocupado de informar as áreas principais em que esta sustentabilidade deveria ser promovida, sem que fosse definido como isto realmente ocorreria.

Apresentados estes argumentos, nos parágrafos que seguem será disposto quem positivou as patentes verdes e como elas foram aplicadas na prática, para no final do estudo verificar se as formas de proteção estatais são suficientes para a promoção desta forma patentária.

\section{PROTEÇÃO DAS PATENTES VERDES}

Após a instituição das patentes verdes pela OMPI, os países iniciaram seus próprios processos de nacionalização desta medida. Todavia, como a proposta das patentes verdes não foi lançada como um tratado, que teria poder de imposição sobre os países, sua adoção ocorreu apenas nas nações que tinham o objetivo de aprimoramento das patentes juntamente com a salvaguarda e proteção do meio ambiente. ${ }^{10}$

Esclarecido este elemento, apresentam-se inicialmente os países que adotaram as patentes verdes no âmbito internacional, partindo em sequência a explanação de como a proteção ocorreu.

\subsection{Países Promotores das Patentes Verdes e a sua Nacionalização.}

A promoção das patentes verdes, apesar de não obrigatória, vem ganhando considerável espaço internacional, à medida que ocorre pressão dos organismos internacionais para a construção de institutos voltados a sustentabilidade.

Tal afirmativa se consubstancia na quantidade de estados membros do programa, que possuem 7 anos, e hoje conta com mais de 20 países, enquanto no ano de 2012 contava com 8

\footnotetext{
${ }^{10} \mathrm{O}$ tratado internacional segundo Rezek (2014, p. 56). "é todo acordo formal concluído entre sujeitos de Direito Internacional Público, e destinado a produzir efeitos jurídicos, sendo em si mesmo, um simples instrumento". Uma vez assinado tal documento ele deve ser cumprido pelas partes, levando-se em consideração o princípio da pacta sunt servanda.
} 
Estados signatários. Apresenta-se inicialmente uma tabela de 2012 desenvolvida por Reis (2012):

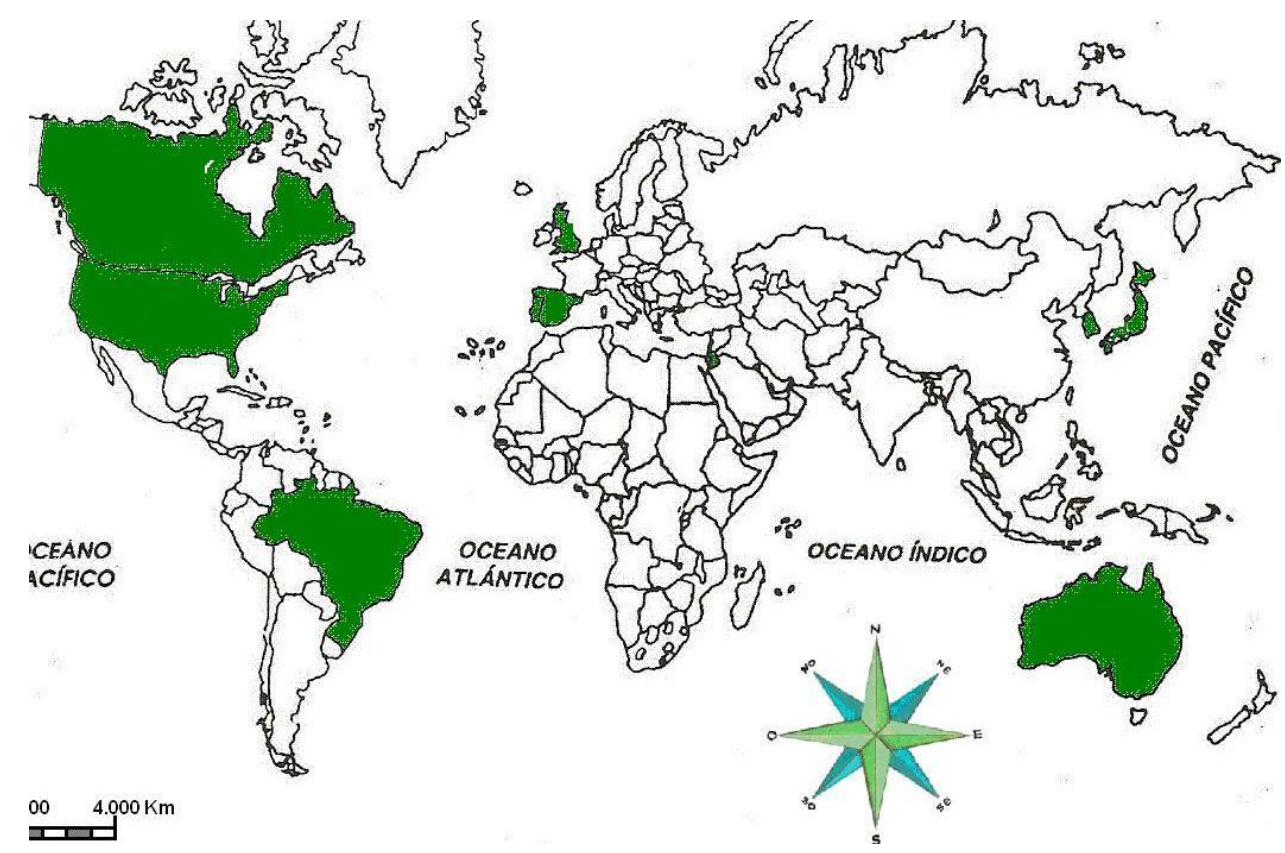

Já em 2016, além dos países acima exteriorizados, ocorreu o ingresso dos seguintes países: China, Índia e Rússia, além de várias nações da união europeia, podendo destacar a França, Alemanha, Polônia, Dinamarca e Suécia. (OECD, 2016)

O aumento na taxa de países participantes da medida representa um avanço no campo do desenvolvimento da sustentabilidade, bem como na força global que a própria OMPI expressa através de suas diretrizes. Isto porque países como China, líder no aumento de pedidos de patente, já adotou o programa de patentes verdes. ${ }^{11}$

Estipulados os países que adotaram a medida, vale destacar quais são as formas de promoção das patentes verdes, tendo em vista que cada país deveria fazê-lo de forma diferenciada. Assim, nos próximos parágrafos este artigo se ocupará de evidenciar as formas de proteção das patentes verdes no Brasil e Espanha, países que participam do projeto das patentes verdes desde sua idealização e exteriorização pela OMPI.

\subsubsection{Patentes Verdes no Brasil}

Seguindo as diretrizes internacionais de promoção das invenções que possuem

\footnotetext{
${ }^{11}$ Os países que mais aumentaram o número de demandas foram: China $(+16,8 \%)$, Coreia do Sul $(+11,5 \%)$, Israel $(+7,4 \%)$, Suíça $(+4,4 \%)$, Japão $(+4,4 \%)$ e Holanda (+3,6\%). (EXAME, 2016).
} 
capacidade sustentável de desenvolvimento, o INPI, em comunhão com a OMPI, lançou no ano de 2012 um projeto piloto de análise de patentes de forma mais célere.

De maneira similar ao que fora enunciado pela OMPI, o Brasil buscou estabelecer diretrizes de incentivo para uma proteção especial das invenções nos seguintes ramos: Energia alternativa, Transporte, Conservação de energia, Gerenciamento de resíduos, Agricultura. (BRASIL, Resolução nº 83, 2013)

Esta lista de áreas de invenção é bastante semelhante àquela elaborada pela OMPI, estando fora apenas a energia nuclear e administrativa, uma vez que estas não fazem parte do programa energético e de desenvolvimento nacional.

Atualmente a relação das parentes verdes está suspensa no Brasil, aguardando análise da terceira fase, tendo sido tutelada pelas Resoluções PR no 131/2014 e PR nº145/2015, que deram continuidade a Resolução ${ }^{\circ}$ 83/2013 que disciplina o tema, trazendo então um objetivo geral para o programa: "Com o objetivo de incentivar a inovação em prol do meio ambiente, o INPI criou a patente verde a qual se trata invenções tecnológicas para obter melhor gestão dos recursos naturais e do meio ambiente". (BRASIL, 2013)

O diferencial estabelecido pelo INPI das patentes verdades em relação as patentes convencionais, está relacionado com o tempo administrativo para análise e concessão ou negativa do pedido patentário. No caso das patentes verdes, o prazo para análise é muito inferior aos pedidos de patentes não verdes. Verifica-se que se geralmente uma patente leva em média 11 anos para ser deferida, enquanto uma patente verde pode levar apenas 9 meses, devido a sua importância para a economia e principalmente para o meio ambiente. (MONACO, 2014)

Vale descrever que os requisitos da proteção das patentes verdes são exatamente os mesmo de uma patente normal, bem como os benefícios do inventor, o que ocorre na verdade, no campo nacional, é uma célere análise do pedido e da tramitação administrativa.

Evidentes estes pontos, pode-se compreender que o Brasil adotou a tendência internacional ditada pela OMPI, criando um sistema de patentes verdes, que busca proteger de maneira mais rápida as propriedades industriais que possuem relação direta com a sustentabilidade.

Analisa-se em sequência a relação das patentes verdes no campo da legislação espanhola, buscando evidenciar possíveis relações e distinções entre o Brasil e o pais europeu. 


\subsubsection{Patente Verde na Espanha.}

As patentes verdes, conforme citado anteriormente, são originárias de um processo internacional de promoção de patentes que causem uma menor degradação do meio ambiente ou que gerem uma produção mais limpa.

Como a medida internacional delegava ao campo administrativo interno o incentivo as patentes verdes, na Espanha seu desenvolvimento ocorreu de forma análoga ao que fora instituído no Brasil, através de um procedimento burocrático acelerado, em que as patentes eram deferidas em tempo inferior ao de costume.

Segundo a Oficina Espanhola de Patentes e Marcas (OEPM), a instituição da patente verde foi bem recebida pelos inventores, que ano após ano estão aumentando a quantidade de depósitos nesta área da propriedade industrial. Tal assertiva pode ser verificada na citação da OEPM que relata o aumento do ano de 2010 para 2015.

Un $2,7 \%$ de las solicitudes corresponde a patentes clasificadas como "patentes verdes", es decir, que pertenecen a sectores tecnológicos respetuososconelmedio ambiente. ActualmenteUn 6,4\% de las solicitudes corresponde a patentes clasificadas como "patentes verdes. (OEPM, 2015)

Destacam-se dois pressupostos no caso espanhol, o primeiro deles está conectado com as temáticas a serem protegidas, que assemelham-se a brasileira, até mesmo porque são ambas derivadas da diretriz internacional, ocorrendo o acréscimo no caso espanhol da temática ligada a modalidades de Gerenciamento de resíduos e Agricultura. (OEPM, 2015)

O segundo pressuposto se evidencia na celeridade das patentes verdes na Espanha, no país europeu a média de tempo para deferimento das patentes verdes ocorre dentro do prazo de 10 a 12 meses, aproximando-se em muito com o que ocorre no Brasil. Todavia, no caso espanhol a redução de tempo é consideravelmente inferior ao brasileiro, se for comparado em termos de percentual.

Se na relação brasileira se obtém um ganho de 12 vezes na celeridade, uma vez que uma patente regular leva em média 12 anos para ser deferida, enquanto a verde 12 meses, na Espanha a média de uma patente normal é de 22 meses, tendo apenas uma redução de $50 \%$ na velocidade de análise.

En concreto, elperiodomedio de concesión de una patente enEspaña es de unos 22 meses conuncoste aproximado de 3.000 euros, a lo que hay que añadirlas anualidades que el inventor debe abonar a la OEPM durante los 20 años de protección máxima de la patente. (FERNANDEZ, 2015, p.49)

Por fim, no tocante as patentes verdes na Espanha, é importante informar que inexiste naquele país qualquer norma especifica voltada a promoção específica deste ramo da 
propriedade industrial, sendo informado que o projeto para alteração da legislação de propriedade industrial na Espanha já prevê a possibilidade da própria norma geral estabelecer as diretrizes para as patentes verdes. (OEPM, 2016)

Diante destes argumentos, verifica-se que ambos os países adotaram medidas muitos semelhantes para a proteção da propriedade intelectual, todavia a consequência da proteção se mostra bastante diferente, uma vez que no final do processo a redução do tempo é enorme no Brasil, enquanto na Espanha é consideravelmente menor.

Frente a esta exposição, no derradeiro item desta pesquisa, discutir-se-á a necessidade de uma diretriz internacional no campo das patentes verdes, tendo em vista as divergências na proteção em cada país.

\section{A OMPI E AS DEMANDAS TRANSNACIONAIS DE PROTEÇÃO DAS PATENTES VERDES}

Conforme relatado nos itens anteriores, foi através de uma diretriz da OMPI que foi idealizada e produzida uma proteção diferenciada para as patentes verdes, porém não fora informado exatamente o que é esta organização, qual sua importância no âmbito internacional e como ela pode interagir na padronização de uma norma para as patentes verdes.

Neste sentido, informar-se-á o que é e para que serve a OMPI, partindo então para verificar a sua competência no âmbito de uma padronização de normativa voltada a proteção das patentes verdes.

\subsection{Característica e Conceito da OMPI}

Vestibularmente informa-se que a OMPI é uma forma de representação de uma Organização Internacional Governamental (OI), que é constituída pela vontade de vários Estados, que juntos criam uma personalidade jurídica própria e com determinada função.

Segundo os dizeres de Mazzuoli (2008, p. 108), uma OI pode ser caracterizada como:

Associação voluntária de sujeitos do direito internacional, criada mediante tratados internacionais (nominado de convênio constitutivo) e com personalidade jurídica distinta de seus membros, que se realiza em um organismo próprio e estável, dotado de autonomia e especificidade, possuindo ordenamento jurídico interno e órgãos auxiliares, por meio do quais realiza os propósitos comuns dos seus membros, mediante os poderes próprios que lhes são atribuídos. 
No tocante a OMPI, esta possui a função de elaborar normativas internacionais de padronização das normas de propriedade intelectual, e para tanto foi construída com base em dois tratados internacionais do século XIX, Tratado de Berna de 1886 e de Paris de 1883, que cuidam especificamente e respectivamente dos direitos do autor e de direito da propriedade industrial.

Segundo o site institucional da organização, "The World Intellectual Property Organization (WIPO) is one of the specialized agencies of the United Nations (UN) system of organizations.", Tendo seu desenvolvimenyo atrelado "The "Convention Establishing the World Intellectual Property Organization" was signed at Stockholm in 1967 and entered into force in 1970." (WIPO, 2016)

Historicamente vale relatar que a OMPI acabou por possuir maior autonomia após o acordo TRIPS, que sob a forma de tratado passou a delimitar as normas básica sobre propriedade intelectual internacionalmente.

A existência dos tratados idealizados pela OMPI representam considerável importância, isto porque tais acordos podem delimitar uma obrigatoriedade mais eficaz no campo do direito internacional público, conforme anuncia a teoria de Trieppel (1868), em que cada Estado é soberano para se submeter a determinadas normas. Assim, quando um país ratifica determinado tratado ele se obriga internacionalmente a cumpri-lo.

Atualmente a OMPI, que possui sede em Genebra na Suíça, se ocupa de promover medidas de desenvolvimento do sistema internacional de propriedade intelectual, buscando difundir as normas e conhecimentos sobre o tema e desenvolver práticas que correlacionem o direito de propriedade com os objetivos gerais da Organização das Nações Unidas.

Isto ocorre porque a OMPI é um órgão especializado da ONU, que cuida de uma área especifica, porém é regido pelas diretrizes gerais da organização que envolve praticamente todos os Estados do globo. De forma análoga podemos verificar a OMS, OMC, OIT como sendo também formas de OI vinculadas a ONU.

Elencados estes pontos, é necessário verificar quais são as demandas transnacionais no campo das patentes verdes, como a OMPI pode tentar resolver estas de demandas, bem como qual a importância da resolução deste tema.

\subsection{Demandas Transnacionais e as Patentes Verdes}

Já tendo sido evidenciado o que são as patentes verdes, bem como o que é a OMPI, é 
imperioso definir o que seriam demandas transnacionais, e depois elenca-las em comparado as patentes denominadas verdes.

Para tanto, utiliza-se os dizeres de Cruz e Bodnar (2013, p.84), ao afirmarem o seguinte:

O fenômeno da transnacionalidade deve ser uma força que opera em duas direções: uma que age na superação do modelo clássico e ultrapassado de Estado Nacional, mediante a criação de novos espaços de governança; e a outra que agrega, fomenta e coordena a ação local dos Estados com efeitos no plano global a partir de pautas axiológicas de amplo consenso.

Assim, levando-se em conta que a transnacionalidade é uma forma de representação de discussões que transpassam a figura propriamente dos Estados e do enclausuramento de normas editadas para demandas exclusivamente locais, uma demanda transnacional se consubstanciaria por uma inquietação que transpassa o Estado, e mais, que emerge de relações de governança transnacional.

Sobre a Governança transnacional novamente nos socorremos de Cruz e Bodnar (2013, p.89), que caracterizam o tema como sendo uma forma de solução para problemas globais através de uma "articulação entre o poder local e o global, baseada na cooperação e na solidariedade".

Isto posto, no campo das patentes verdes, a questão a ser discutida e possivelmente solucionada está diretamente relacionada com a necessidade de um diálogo global para a adoção de medidas transfronteiriças no real desenvolvimento das patentes verdes.

Se de um lado a OMPI adotou uma medida internacional para a proteção das patentes verdes, de outro ele deixou a cargo dos Estados as formas com que a promoção da medida se desenvolveria, o que acaba por representar grandes diferenças, como a que ocorre entre Brasil e a Espanha.

Evidente isto, e levando em consideração que um produto revolucionário ao meio ambiente, e sustentabilidade como um todo, não pode ser protegido em um único país, mas sim precisa correr globalmente, é necessário que se adote uma medida transnacional pela OMPI para responder a esta demanda global.

No intuito de discutir a problemática apresentada, no último item desta pesquisa almeja-se evidenciar algumas formas de resposta transnacional adota pela OMPI no campo das patentes verdes. 


\subsection{Respostas Transnacionais Na Área Das Patentes Verdes.}

Diagnosticada a existência de demandas transnacionais no campo das patentes verdes, é preciso que uma forma de resposta seja dada, a fim de que as pessoas que buscam desenvolver mecanismos de proteção voltados ao desenvolvimento sustentável ${ }^{12}$ sejam favorecidss.

Para tanto, não basta que a OMPI tenha informado as áreas da propriedade industrial que merecem benefícios, e ter igualmente direcionado estes benefícios para o âmbito administrativo de cada país. É necessário que seja adotado uma diretriz internacional para proteção das patentes verdes.

Como forma de solucionar a problemática global o presente artigo enumera algumas possibilidades, que podem caminhar tanto no âmbito interno, como ainda na esfera internacional da propriedade industrial, principalmente no campo das patentes de invenção.

No que tange o âmbito interno, a OMPI poderia determinar que cada país reduzisse os custos de proteção de uma patente, quando essa fosse elencada como sendo verde. Tal diretriz se adotada internacionalmente poderia reduzir drasticamente o custo operacional das patentes, o que geraria um incentivo econômico eficiente.

A medida financeira interna se mostra válida, porém deve ser idealizada no campo global, isto porque quando de uma proteção patentária o inventor deve requisitar o registro e o pagamento de taxas em todos os países que almeja proteger, o que, a depender da possível lucratividade da invenção gera altos custos.

Apesar da simplicidade de tal medida, uma problemática se atrela a ela de forma praticamente instantânea. Em caso dos países adotassem uma taxa próxima a zero para as patentes verdes, quem arcaria com o custo desta forma especial de patente de invenção?

Atualmente, mesmo que com possível defasagem, são as taxas de proteção que financiam todo o sistema de análise de propriedade industrial. Assim, caso inexistisse o pagamento de valores para patentes verdes, a OMPI seria obrigada a idealizar uma forma secundaria de repasse de valores parar os órgãos administrativos internos. (DEL NERO, 2004, p.26)

Isto posto, a medida interna, apesar de válida, gera dilemas complexos e que

\footnotetext{
${ }^{12} \mathrm{O}$ desenvolvimento global e qualitativo, aliado à proteção efetiva do meio ambiente, constitui um dos grandes desafios para as sociedades contemporâneas. Estabelecer as diretrizes sustentáveis para um futuro com mais prudência ambiental e com a gestão adequada dos riscos é uma das principais tarefas do Direito Ambiental. Assim, o objeto deste estudo é desenvolver a concepção da sustentabilidade enquanto princípio jurídico. (FREITAS, 2009, p. 107.)
} 
necessitam interação diretamente com as legislações e orçamentos de todos os países membros da OI.

De outra feita, no campo internacional, duas medidas poderiam teoricamente ser adotadas, a primeira se consubstancia nas delimitações teórico práticas que um item precisa ter para ser patenteado. Aduz-se aqui uma relativização das características básicas para que um bem seja considerado uma patente de invenção.

Tal medida, apesar de possível, não gera no final do processo produtos realmente inovadores, o que é base de todo o sistema de patentes. Deste modo, não é medida cabível a flexibilização dos elementos da patente, isto porque é somente através deles que se busca instigar realmente o inventor.

Todavia, de outra forma, no tocante ao tempo de proteção se verifica um possível fomento a proteção de novas tecnologias, voltadas ao campo da sustentabilidade e desenvolvimento sustentável. Se atualmente o prazo de proteção de uma patente é de 20 anos, para o caso de uma patente verde este prazo poderia ser ampliado para 25, ou mais. (DEL NERO, 2004, p.29)

A adoção de uma ampliação na proteção das patentes verdes deveria desta forma ocorrer na esfera da OMPI, sendo aplicada em todos os países que seguem normas gerais de PI, fazendo pouco importar a real celeridade administrativa de cada país ou os custos e taxas operacionais internas.

Uma diretriz elaborada neste sentido buscaria promover a produção de patentes verde, ao mesmo tempo que não onera os sistemas de cada país, e sim gera concretos e uniformes benefícios na esfera internacional.

Para que a medida fosse adotada, no entanto, seria preciso que a OMPI promovesse a elaboração de um tratado internacional voltado ao tema, delimitando então o que se entende por patente verde e qual o mecanismo de promoção desta medida em caráter internacional, a fim de então suprir uma demanda transnacional.

\section{CONSIDERAÇÕES FINAIS}

Com tudo que fora relatado, vários pontos foram observados, buscando-se durante toda a pesquisa um estudo verificador da existência de uma demanda transnacional no campo da proteção e promoção das patentes verdes, bem como de respostas a serem emitidas pela OMPI neste sentido. 
Para tanto, foi necessário estabelecer uma base sobre o tema, sendo abordado a criação e conceituação do sistema de patentes, dando destaque para as patentes verdes, que são objeto central da presente pesquisa.

Em sequência, realizou-se a construção teórica de como as patentes verdes foram idealizadas, difundidas e instituídas em diferentes países, demonstrando que elas estão enquadradas em rol da OMPI, porém com promoção diversa em cada nação que é protegida.

Ainda no segundo item foram verificadas as formas de proteção das patentes verdes em dois países que iniciaram, já no começo dos anos 2010, o trabalho com este ramo das patentes de invenção. Tendo sido evidenciado que a forma de promoção das patentes verdes é semelhante, porém a consequência é bastante diversa.

Isto porque, enquanto no Brasil a celeridade administrativa gera um ganho de 12 vezes na velocidade da análise, em solo especial a vantagem para o inventor é de menos de 2 vezes, o que representa um incentivo muito baixo para uma área que se encontra ou ao menos narrase, como almejada para o desenvolvimento sustentável.

Compreendeu-se nesta análise preliminar, que apesar de existir vantagens das patentes verdes em relação as patentes de invenção convencional, esta promoção ocorre de forma diversa em cada país, podendo representar em alguns, maior vantagem prática do que em outros.

Analisados estes dois itens, em um terceiro item, passou-se a compreender a necessidade de respostas transnacionais para as demandas das patentes verdes, isto porque os inventores protegem os seus produtos em mais de uma nação ao mesmo tempo, contudo, como a promoção ocorre de forma diversa em cada país, apesar das áreas das patentes verdes serem as mesmas, uma resposta local não supre a necessidade global.

Como medidas apontadas no estudo, verificou-se a possibilidade de isenção de taxas administrativas para as patentes verdes, o que pode ser problemático devido a gestão financeira, ou ainda o prolongamento do tempo de exploração exclusiva, que passaria de 20 para 25 anos.

Analisados todos argumentos, a hipótese restou completamente confirmada, uma vez que é necessária uma reforma no pensamento transnacional para a real efetivação, valorização e promoção das patentes verdes no cenário transnacional da propriedade industrial.

\section{REFERÊNCIAS}

BARBOSA, Denis Borges; JABUR, Wilson Pinheiro; SANTOS, Manoel Joaquim 
Pereira dos. Propriedade intelectual: criações industriais, segredos de negócio e concorrência desleal. São Paulo, SP: Saraiva, 2007.

BINCTIN, Nicolas. Droit de la propriéte intellectuelle. LGDJ : Paris, 2010.

BRASIL, República Federativa do. Constituição Federal: Artigo 5, XXVII. Brasília. Disponível em: http://www.planalto.gov.br/ccivil_03/constituicao/constituicaocompilado.htm. Na da de 22 de julho de 2016.

BRASIL, República Federativa do. Lei no 9.279, de 14 de maio de 1996. Brasília. Disponível em: http://www.planalto.gov.br/ccivil_03/leis/L9279.htm. Na data de 22 de junho de 2016.

BRASIL, República Federativa do. Resolução n⿳ 83/2013: Prorroga e expande o Programa Piloto de exame prioritário de pedidos de Patentes Verdes no âmbito do INPI e dá outras providências. Disponível em http://www.inpi.gov.br/legislacaoarquivo/docs/resolucao_83-2013_prorrogacao_patentes_verdes.pdf. Na data de 22 de junho de 2016.

CRUZ, Paulo Marcio, BODNAR, Zenildo. A governança transnacional ambiental na rio + 20. Revista do CEJUR/TJSC: Prestação Jurisdicional, v. 1, n. 01, p. 79-103, dez. 2013.

DEL NERO, PatriciaAurelia. Propriedade intelectual: a tutela jurídica da biotecnologia. 2. ed. rev. atual. eampl. São Paulo, SP: Revista dos Tribunais, 2004.

DIRPA, Diretoria de Patentes. Manual para o depositante de patentes. Disponível em: http://www.inpi.gov.br/menu-servicos/patente/arquivos/manual-para-o-depositante-depatentes.pdf. Na data de 22 de junho de 2016.

EXAME, Revista. EUA se mantêm como país que registra mais patentes no mundo. 16/03/2016. Disponível em: http://exame.abril.com.br/economia/noticias/eua-semantem-como-pais-que-registra-mais-patentes-no-mundo. Na data de 22 de junho de 2016. 
FERNANDEZ, Rebeca. La burocracia y loscostesexcesivosahogan a los inventores españoles: El Confidencial. Disponível em: http://www.elconfidencial.com/tecnologia/2015$\underline{11-30 / \text { creatividad-perseverancia-y-control-del-gasto-el-periplo-de-los-inventores- }}$ espanoles_1108487/. Na data de 22 de junho de 2016.

FREITAS, Juarez. Sustentabilidade: Direito ao Futuro. São Paulo: Editora Fórum, 2009.

INPI, Instituto Nacional da Propriedade Industrial. Disponível em: http://www.inpi.gov.br/index.php?option=com_content\&view $=$ article\&id=107\&Itemid=65, na data de 7 de julho de 2016.

MAZZUOLI, Valerio de Oliveira. Direito internacional público: parte geral. 4. ed. rev., atual. eampl. São Paulo, SP: Revista dos Tribunais, 2008.

MONACO, Rafael. Brasil ocupa penúltima posição em ranking de patentes válidas: relatório da Organização Mundial de Propriedade Intelectual mostra que, entre 20 países analisados, o Brasil só ganha da Polônia. Por aqui, a espera por uma concessão pode ultrapassar 14 anos. Abril de 2014. Disponível em: http://www.portaldaindustria.com.br/cni/imprensa/2014/04/1,35905/brasil-ocupa-penultimaposicao-em-ranking-de-patentes-validas. na data de 07 de março de 2016.

OECD. Organisation for Economic Co-operation and Development. Disponível em: http://www.oecd.org/env/indicators-modelling-outlooks/green-patents.htm. Na data de 22 de junho de 2016.

OEPM, Oficina Espanhola de Patentes e Marcas. La OEPM es el Organismo Público responsabledel registro y laconcesión de las distintas modalidades de Propiedad Industrial. Disponível em: http://www.oepm.es/es/index.html. Na data de 22 de junho de 2016.

PASOLD, Cesar Luiz. Metodologia da Pesquisa Jurídica: Teoria e Prática, 12 ed. rev. São Paulo: Conceito Editorial, 2011, p. 205. 
PIMENTEL, Luiz Otávio. Propriedade Intelectual e Universidade: aspectos legais. Florianópolis: Fundação Boiteaux, 2005.

REIS, Patrícia Carvalho dos e SANTOS, Douglas Alves. Patentes Verdes no Brasil. Rio deJaneiro18 de Junho de 2012.Disponível em:www.desenvolvimento.gov.br/arquivos/dwnl_1340223723.ppt. Na data de 22 de junho de 2016.

REZEK, José Francisco. Direito internacional público: curso elementar. 15. ed. rev., São Paulo, SP: Saraiva, 2014.

SANTOS, Ozéias. Marcas e patentes, propriedade industrial São Paulo: INTLEX informações jurídicas Ltda., 2001.

TAFFOREAU, Patrick. Droit de la Propriété intellectuelle: propriété littéraire et artistique, propriété industrielle et droit international. Gualianoediter: Paris, 2004.

WACHOWICZ, Marcos; PALAO MORENO, Guillermo; PEREIRA, Alexandre Libório Dias. Propriedade intelectual: inovação e conhecimento. Curitiba, PR: Juruá Ed., 2010

WIPO, World IntellectualPropertyOrganization. The Concept of Intellectual Property, Genebra. Disponível em: http:/www.wipo.int/export/sites/www/aboutip/en/iprm/pdf/ch1.pdf. Na data de 21 de julho de 2016. 